\title{
A Study of the electronic structure of CdS Nanocrystals using density functional theory
}

Thekra Kasim

\author{
Department of Physics, College of Science, University of Baghdad, Baghdad, Iraq
}

E-mail: Thekra_alani@yahoo.mail

\begin{abstract}
Density Functional Theory at the generalized-gradient approximation level coupled with large unit cell method is used to simulate the electronic structure of (II-VI) zinc-blende cadmium sulfide nanocrystals that have dimensions $2-2.5 \mathrm{~nm}$. The calculated properties include lattice constant, conduction and valence bands width, energy of the highest occupied orbital, energy of the lowest unoccupied orbital, energy gap, density of states etc. Results show that lattice constant and energy gap converge to definite values. However, highest occupied orbital, lowest unoccupied orbital fluctuates indefinitely depending on the shape of the nanocrystal.
\end{abstract}

Key words

Electronic structure, nanocrystals, Density functional theory.

Article info.

Received: Apr. 2014

Accepted: May. 2014

Published: Sep. 2014

دراسة التركيب الاكتروني لبلورات كربيتيت الكادميوم (CdS) النانوية باستخدام نظرية دالة الكثافة

$$
\text { قسم الفيزياء, كلية العلوم, جامعة بغدادي, بغداد, العراق الق الرحيم }
$$

باستخدام نظرية دو ال الكثافة (DFT) مع طريقة (LUC) تمت در اسة التركيب الالكتروني لكبريتيت الكادميوم ذات تركيب

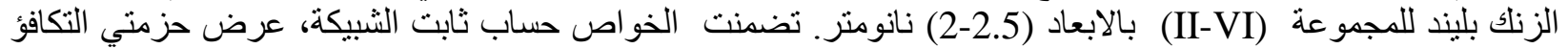

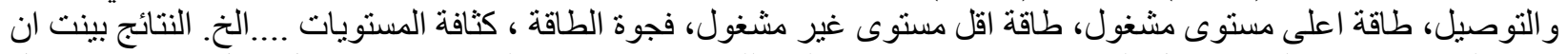
ثابت الثبيكة وفجوة الطاقة تصل الى قئم محددة. بالاضافة الى ذللك كلا من طاقة اعلى مستوى مشغول و اقل مستوى مشغول تكون غير محددة تعتمد على شكل البلورة النانوية.

\section{Introduction}

The size-dependent properties of semiconductor nanocrystals have attracted considerable interest from physicists and chemists both because of the scientific questions they raise and because of their potential technological applications[1]. As the investigation of size-dependent properties progresses, experimental techniques for nanocrystal synthesis and analysis continue to improve [2]. At the same time, theoretical methods for computing nanocrystal properties develop increasing accuracy.

Past theoretical studies of electronic and structural properties have included effective mass calculations, tight binding calculations, band-structure discretization, and other approaches [3,4]. Such varied schemes have been suggested because semiconductor nanocrystals are in a difficult size regime: they are generally too big for molecular techniques 
but too small for a bulk computation that ignores the nanocrystal surface.

Cadmium sulfide is the inorganic compound with the formula $\mathrm{CdS}$. It is a direct band gap semiconductor (gap 2.42 eV) [5]. As well as this obvious property others properties result. $\mathrm{CdS}$ used in manufacturing of photoresistors (light dependent resistors) sensitive to visible and near infrared light. CdS was also one of the first semiconductor materials to be used for thin-film transistors (TFTs)[6]. Thin films of Cadmium Sulfide can be piezoelectric and have been used as transducers which can operate at frequencies in the $\mathrm{GHz}$ region. Cadmium sulfide is a yellow solid [6]. Cadmium sulfide has, like zinc sulfide, two crystal forms; the more stable hexagonal wurtzite and cubic zinc- blende structure. In both of these forms the cadmium and sulfur atoms are four coordinate.

The present work will be involved in calculating electronic properties of $\mathrm{CdS}$ nanocrystals as the size and shape of these nanocrystals change. We were used density functional theory at the generalized-gradient approximation level (Perdew, Burke, and Ernzerhof PBE approximation) coupled with large unit cell method (LUC- DFT) to simulate the electronic structure of $\mathrm{CdS}$ which is a well developed theory that had been applied repeatedly for the nanocrystals electronic structure [7-9].

\section{Theory}

The large unit cell method (LUC) which can be used to simulate systems of periodical symmetry such as the bulk or surfaces of ordinary crystals. The LUC is adopted for the simulation of the electronic structure of nanocrystals in conjunction with the $\mathrm{k}=0$ approximation ( $\mathrm{k}$ is the reciprocal wave vector). This approximation is used to drop sums of contributions from other points in $\mathrm{k}$ space except the origin [10-12].

This is translated in nanocrystals structure by saying that we have a limited translational symmetry in the inside "core" of the nanocrystal only. Since the inside core of the nanocrystal has a well-defined 3D symmetry structure such as in the present zincblende structure, we optimize the structure by optimizing the lattice constant of the inner core only. This method can be used to simulate nanocrystals surfaces by adopting the $\mathrm{k}=0$ approximation but with more elaborate optimization procedure. Density functional theory at the generalized gradient approximation level coupled with large unit cell method (LUC-DFT) is used to simulate the electronic structure of zincblende cadmium sulfide nanocrystals. Four LUC cores are considered in the present work 8, 16, 54, and 64 atoms [13].

In order to simulate zincblende nanocrystals electronic structure using LUC method two kinds of cells are available: primitive and Bravais cell multiplets (Fig. 1 and 2 respectively). The main difference between these two kinds of cells is the shape and its associated surfaces. Primitive cells are parallelograms while Bravais cells are cubic in shape [12]. This difference in shape results in many fluctuations in the electronic structure of zinc-blende structured materials [9-12]. However, the present fluctuations are the strongest between the investigated materials. Two primitive cell multiplet cores are investigated namely: 16, 54 atoms. Two Bravais cell multiplet cores are investigated namely 8 and 64 atoms. 


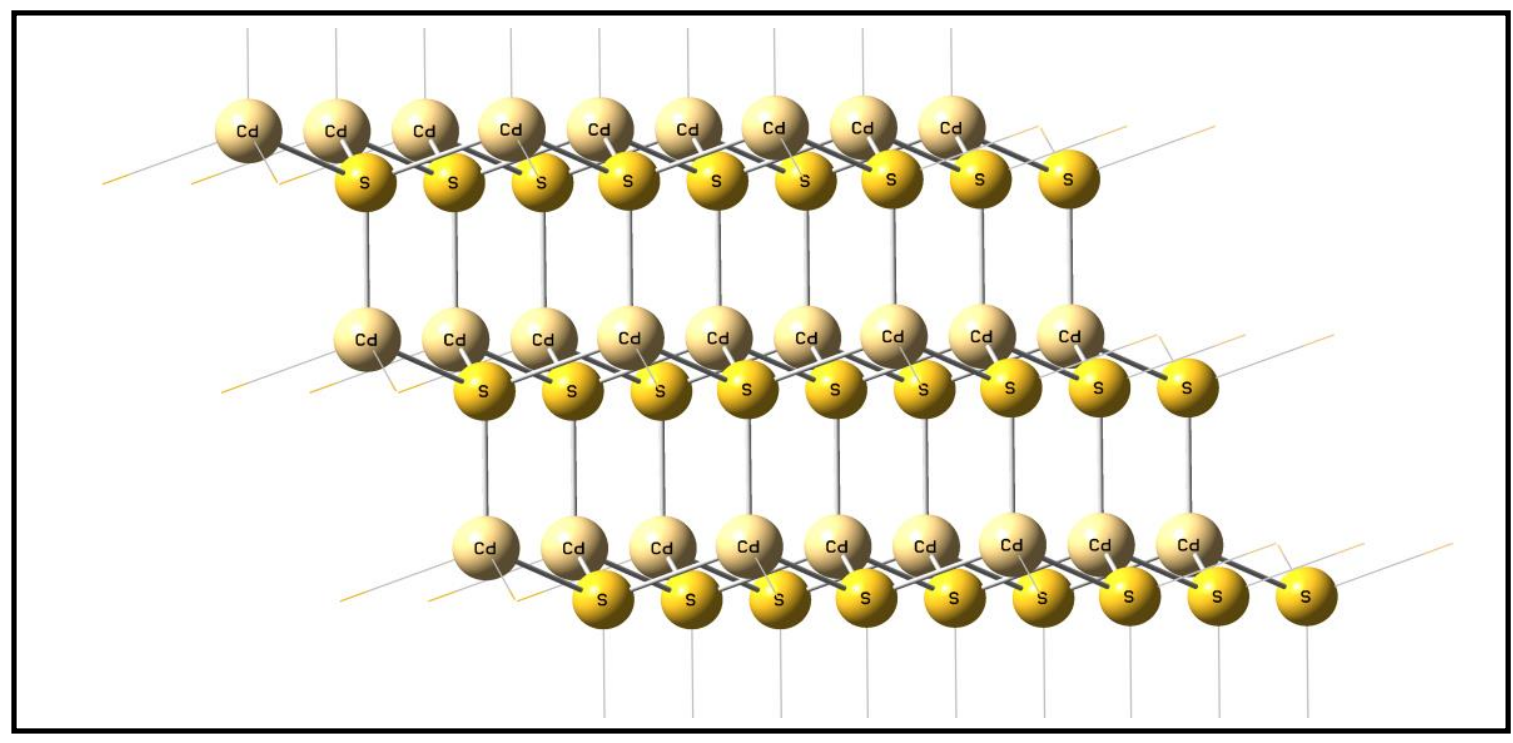

Fig. 1: (color online) CdS 54 atoms core LUC (parallelepiped shape primitive cell multiplet).

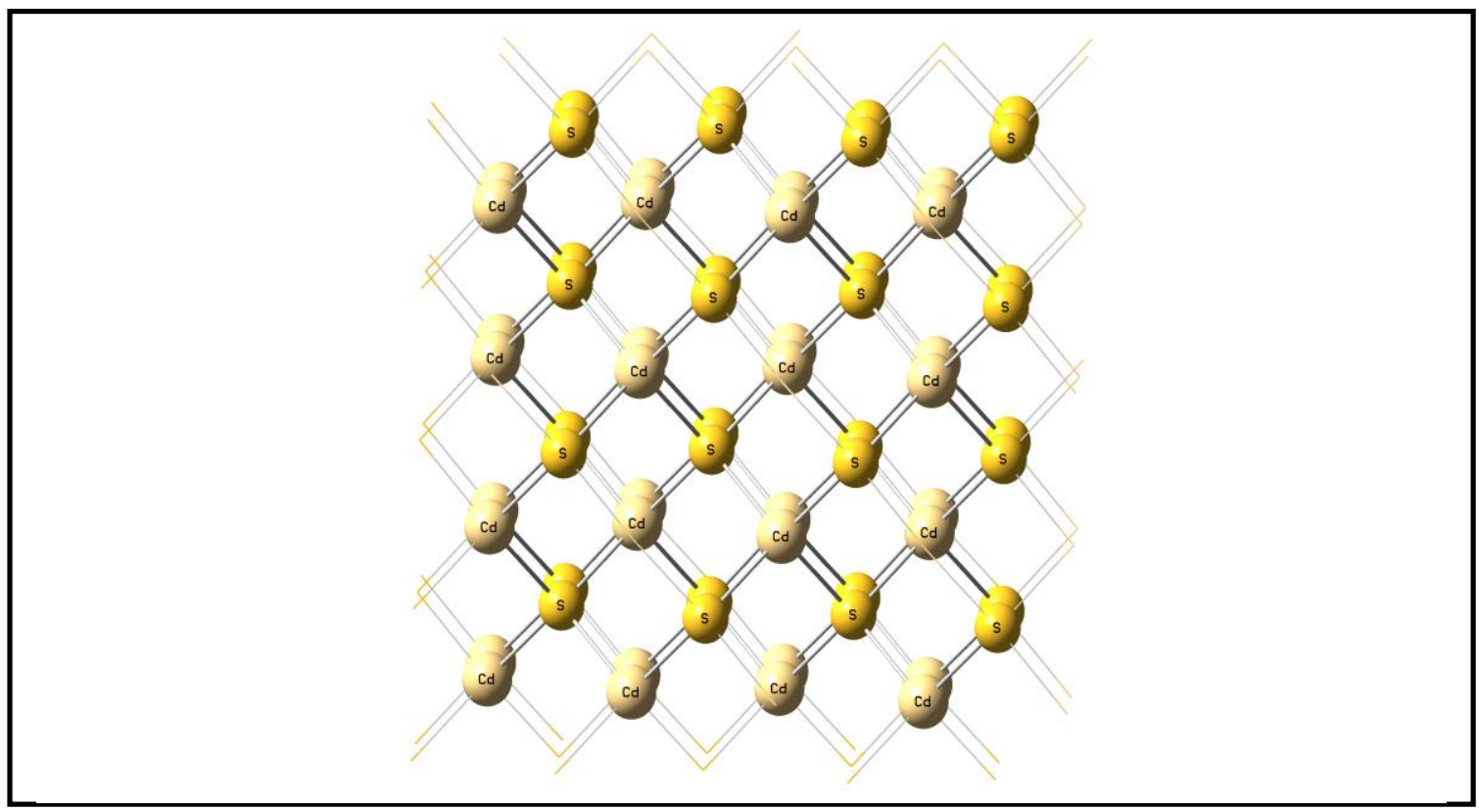

Fig. 2: (color online) CdS 64 atoms core LUC (cubic Bravais cell multiplet).

\section{Results and disscussions}

To optimize core structure the lattice constant is needed to be optimized. In the optimization procedure we pick the minimum energy structure for every investigated LUC. From the set of minimum structures we can draw the following figures for the core part : Figs. 3 and 4 show the total energy for 54, 64 atoms respectively of $\mathrm{CdS}$ nanocrystal as a function of lattice constant from which we obtained the equilibrium lattice constant. This behavior is due to the attraction forces that take place at the large distance between atoms. The stability of the nanocrystal was at the equilibrium when lattice constant equal to $0.55 \mathrm{~nm}$, while the attraction forces between the atoms equal to the repulsion [8]. 


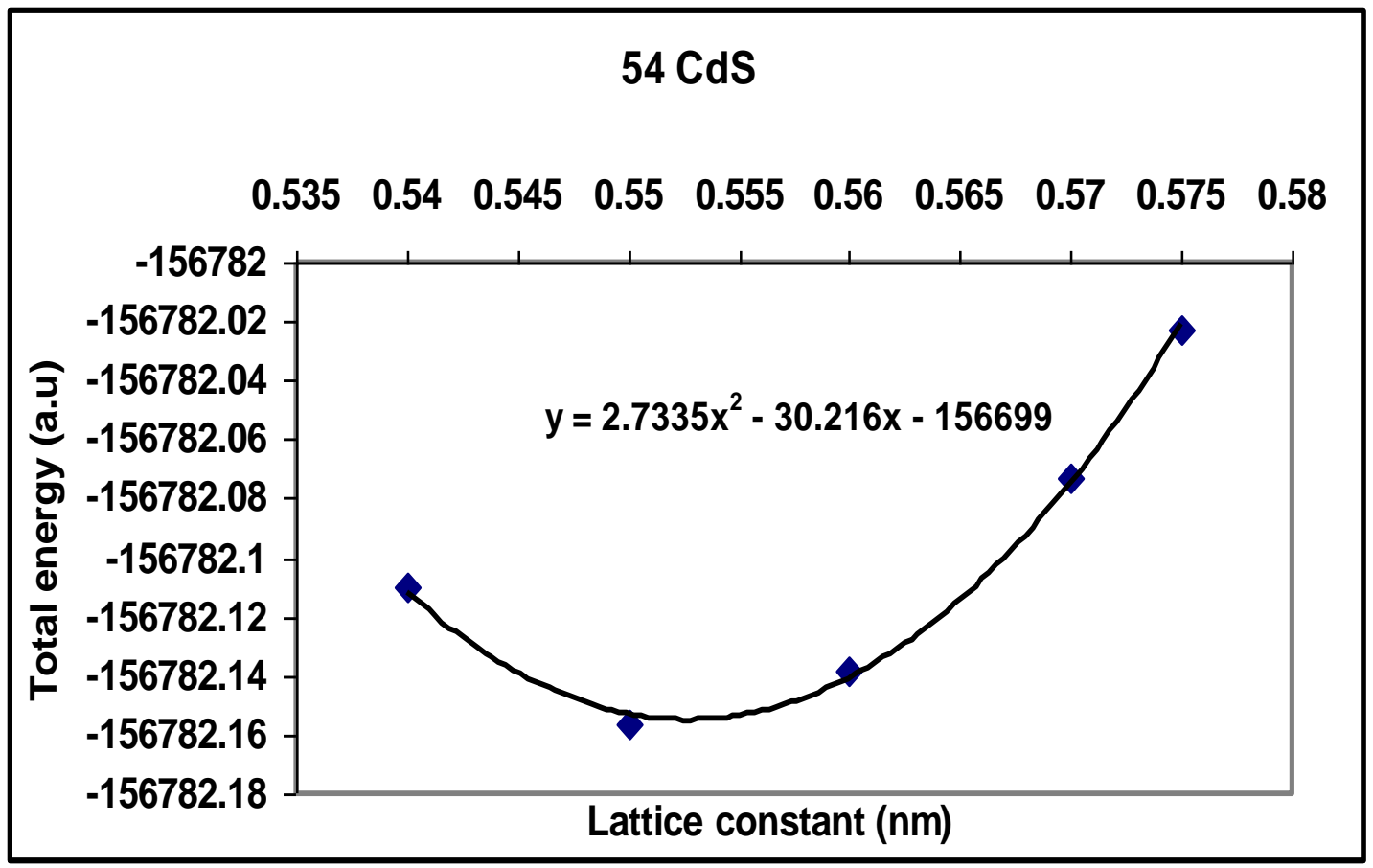

Fig.3: Total energy of 54 atoms of CdS nanocrystal core as a function of lattice constant.

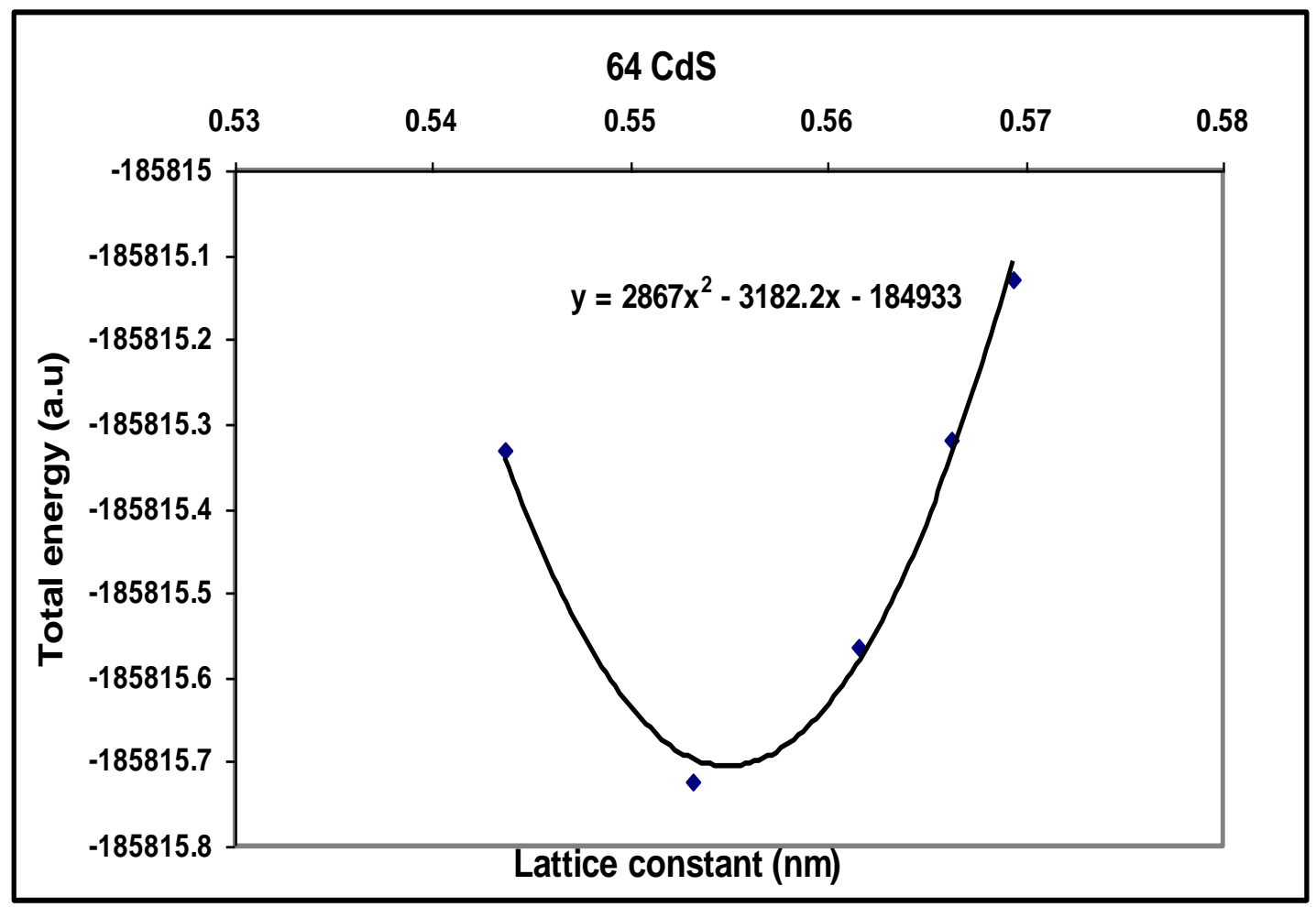

Fig.4: Total energy of 64 atoms of CdS nanocrystal core as a function of lattice constant. 
In Fig. 5 the lattice constant of $\mathrm{CdS}$ nanocrystals core shows a decreasing trend as the number of core atoms increase. The value of lattice constant decreases from the value $0.57 \mathrm{~nm}$ and converges to $0.55 \mathrm{~nm}$. A similar behaviour is observed in previous studies [14-17].

Fig. 6 shows the variation of the energy gap of $\mathrm{CdS}$ nanocrystals with the number of core atoms the usual decrease in the core energy gap as the number of core atoms increase that is supported by the quantum confinement theory $[18,19]$. This quantum size effect can be explained qualitatively by considering a particle-in-abox like situation where the energy separation between the levels increases as the dimensions of the box are reduced. Thus, one observes an increase in the band gap of the semiconductor with a decrease in the particle size.

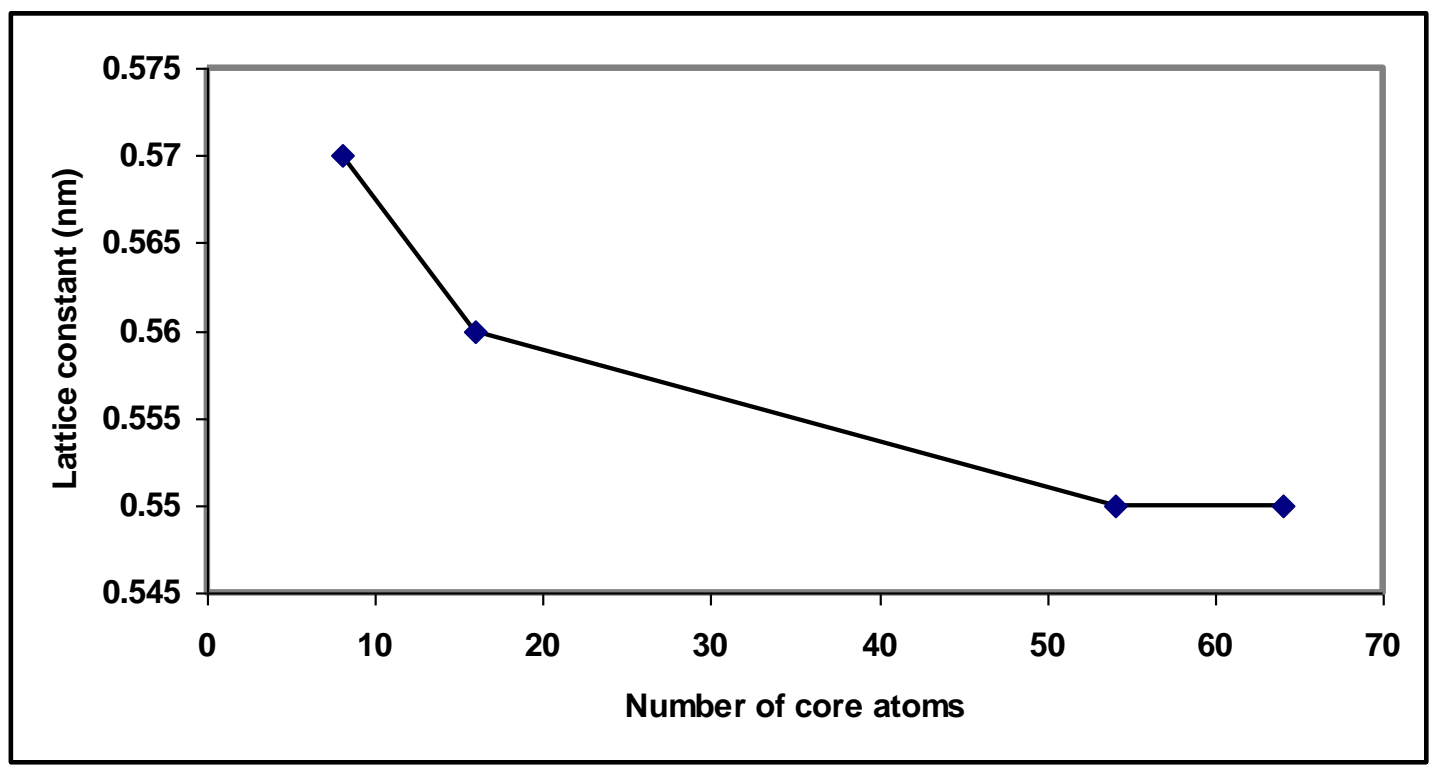

Fig. 5: Lattice constant variation with the number of core LUC atoms of CdS nanocrystals.

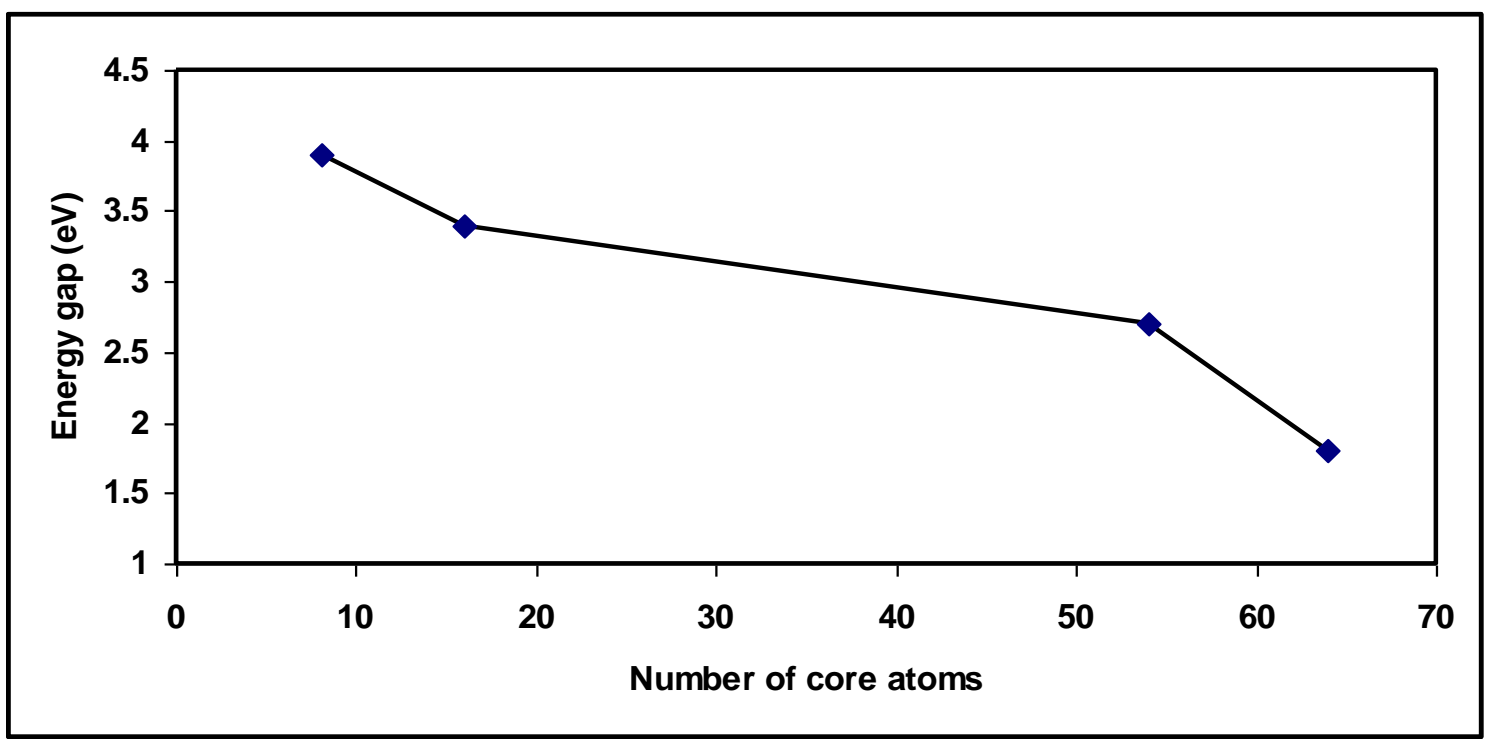

Fig. 6: Energy gap variation with the number of core LUC atoms of CdS nanocrystals. 
Valence and conduction bands in Fig. 7 show the same trend of shape effects. Cubic cells (8, 64 atoms) have wider bands than parallelepiped cells. This effect was also recognized but with less obvious shape effects in previous studies $[9,10]$. The same is true in Fig. 8 for the HOMO and LUMO orbital energies. HOMO and LUMO orbitals do not only show shape effects, but also continues to fluctuated indefinitely due to the formation of different surfaces in larger nanocrystals [10]. Other quantities that can be derived from HOMO and LUMO orbital energies include affinity, ionization energy and Fermi level. Affinity and ionization potential is connected approximately by a negative sign to LUMO and HOMO energies respectively [16]. Fermi level is the average of LUMO and HOMO energies [20]. As a result of these relations, these three quantities also have the same shape effect that affect HOMO and LUMO energies.

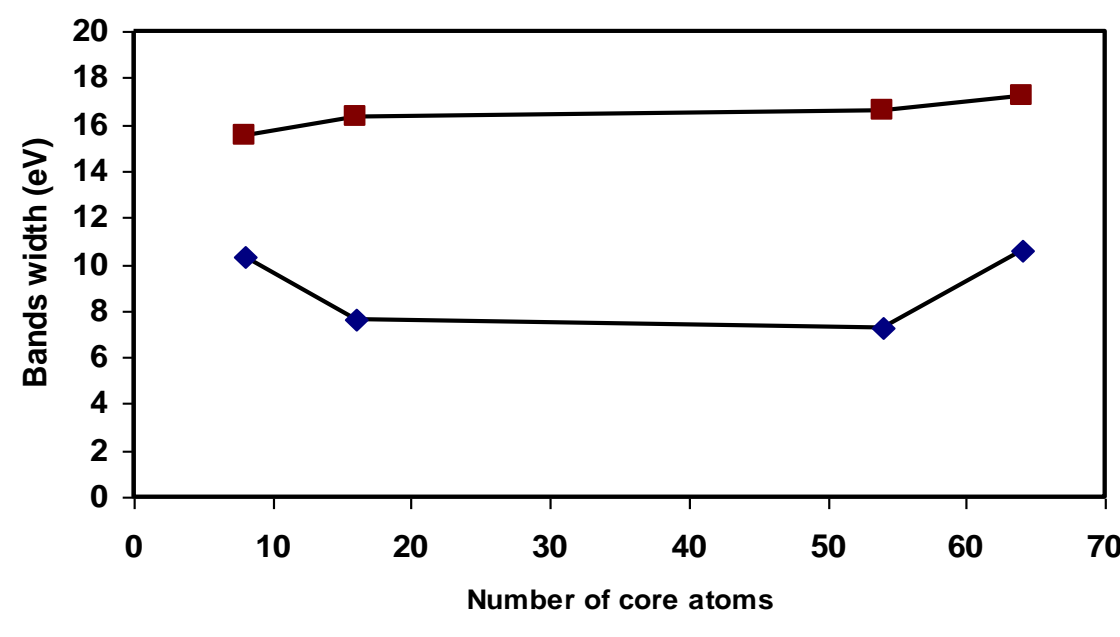

$\checkmark$ Conduction

$\rightarrow$ - Valence

Fig. 7: Valence and conduction bands variation with the number of core LUC atoms of InP nanocrystals.

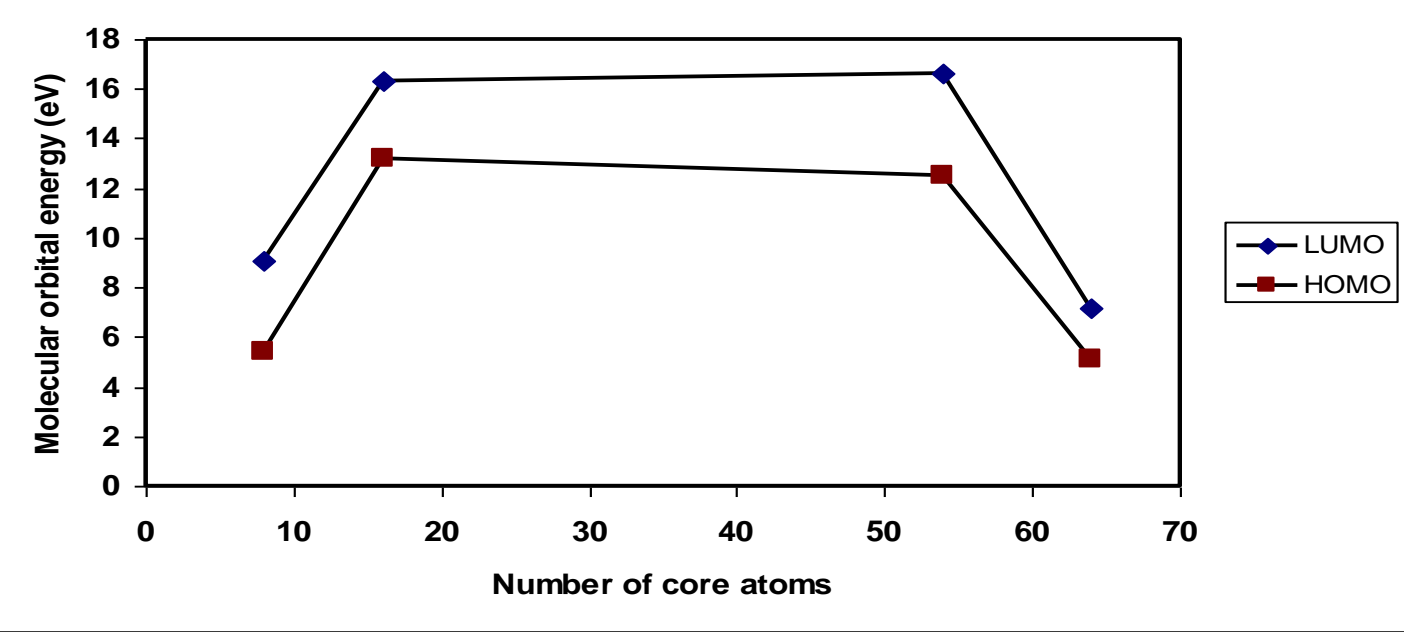

Fig. 8: Energy of the LUMO and HOMO levels variation with the number of core LUC atoms of InP nanocrystals. 
Figs. 9a and 9b summarize the physics of many of the previous figures. Degeneracy of states of 54 and 64 atom LUCs show the above valence and conduction band widths variation between primitive and Bravais cells. The variation of the energy of HOMO and LUMO movements are also obvious in this figure. The highest degeneracy of primitive cells is higher than that of Bravais cells. This shows that symmetry of primitive cells is more definite than Bravais cells.

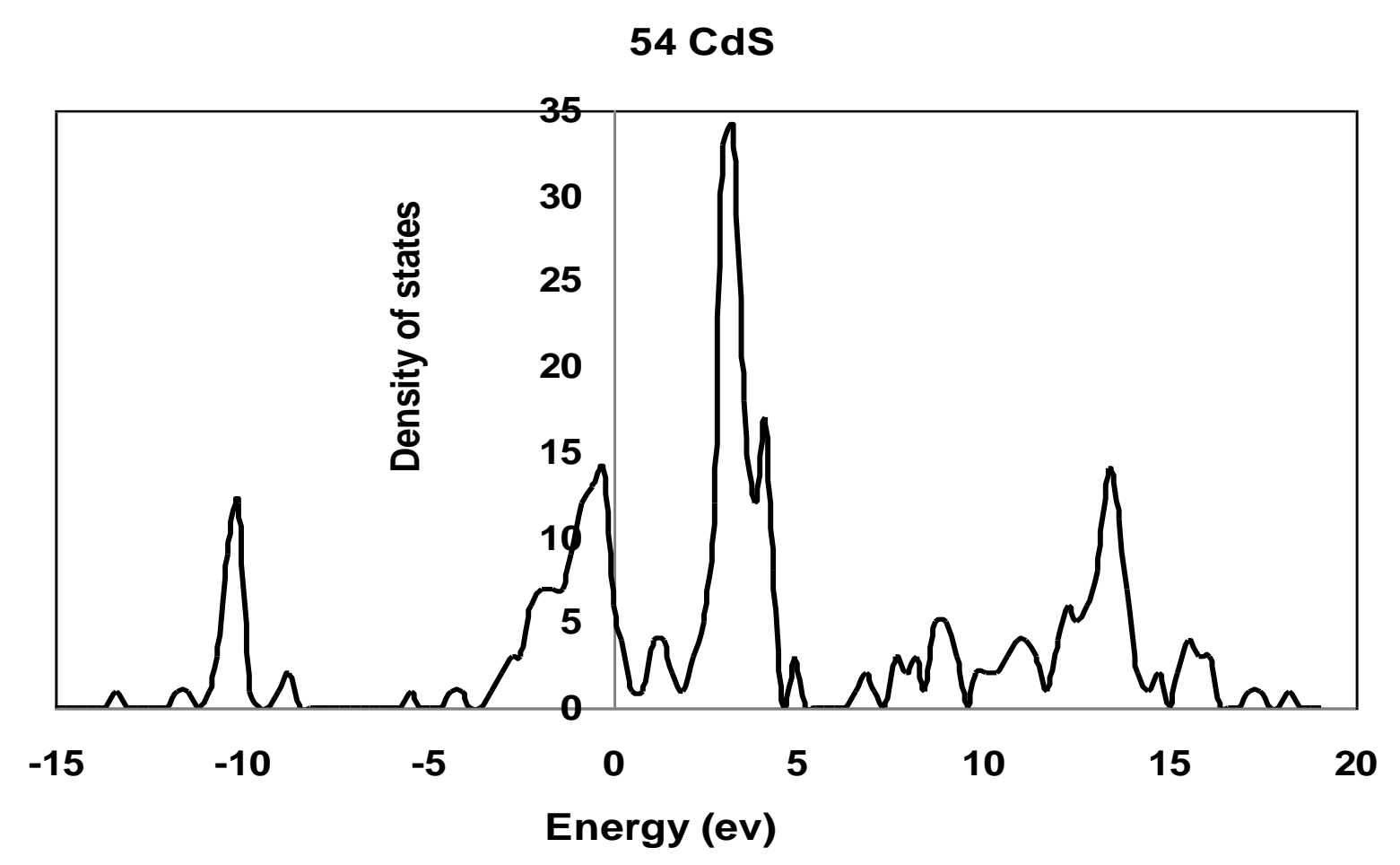

(a)

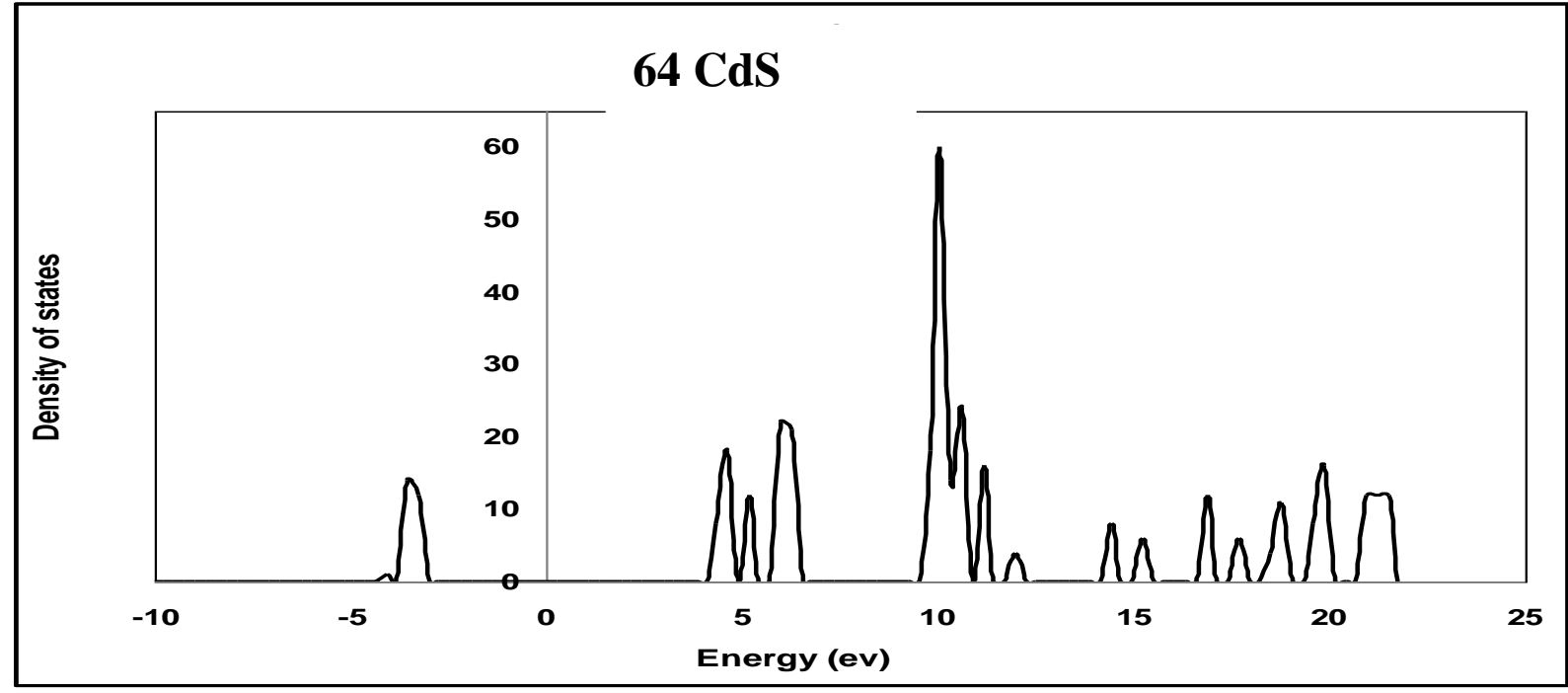

(b)

Fig. 9: Degeneracy of states of 54 and 64 atom LUCs (a and $b$ respectively) as a function of energy levels are shown in this figure. 


\section{Conclusions}

The main conclusion of the above results indicate that the lattice constant and energy gap will be decrease with increase core atoms, Valence band, conduction band, energy of the HOMO and LUMO orbitals all show shape effects. Degeneracy of states as a function of energy show a summary of the above mentioned shape properties.

\section{References}

[1] T. Vossmeyer, J. Phys. Chem., 98 (1994) 7665

[2] A. I. Ekimov, F. Hache, M. C. SchanneKlein, D. Ricard, C.Flytzanis, I.A. Kudryavtsev, T. V. Yazeva, A. V. Rodina, and 1. L.Efros, J. Opt. Soc. Am., B 10 (1993) 100.

[3] L. M. Ramaniah and S. V. Nair, Phys. Rev., B 47 (1993) 7132.

[4] A. Franceschetti and A. Zunger, Phys. Rev. Lett., 78 (1997) 915.

[5] D.Lincot, Gary Hodes Chemical Solution Deposition of Semiconducting and NonMetallic Films: Proceedings of the International Symposium The Electrochemical Society, ISBN 1-56677433-0 (2006).

[6] P.K. Weimar, Proc. IRE, 50, 6 (1962) 1462-1469.

[7] M. T. Hussein, T. Kasim and M. A. Abdulsattar, Indian J. of Physics, published online 11 June (2013) 1079-1085.

[8] M. A. Abdulsattar, Electronic Materials Letters, 6, 3 (2010) 97-101.

[9] M. A. Abdulsattar, Physica E, 41, 9 (2009) 1679-1688.
[10] N. H. Aysa, M. A. Abdulsattar, and A. M. Abdul-Lettif, Micro and Nano Letters, 6, 3 (2011) 137-140.

[11] Mohammed T. Hussien, Akram H. Taha and Thekra Kasim, Intcryational Journal of Application or Innovation in Engineering and Management (IJAIEM) 2, 5, May (2013) 418-424.

[12] H. M. Abduljalil, M. A. Abdulsattar, and S. R. Al-Mansoury, "SiGe nanocrystals core and surface electronic structure from $\mathrm{Ab}$ initio large unit cell calculations," Micro \& Nano Letters, 6 (2011) 386.

[13] M. A. Abdulsattar, Solid State Sciences, 13, 5 (2011) 843-849.

[14] N. A. Nama, M. A. Abdulsattar and A. M.Abdul-Lettif, J. of Nanomaterials, 2010 (2010) ID 952172.

[15] J. P. Perdew and Y. Wang, Phys. Rev., B 45, 13 244(1992).

[16] S.J. Sque, R. Jones, and P.R. Briddon, Phys. Rev. B 73, 085313 (2006).

[17] J. B. Foresman and A.E. Frisch, "Exploring Chemistry with Electronic Structure Methods: A Guide to Using Gaussian", $2^{\text {nd }}$ edition, Gaussian Inc. (1996).

[18] Nesher G., Kronik L., Chelikowsky J. ' $\mathrm{Ab}$ initio absorption spectra of $\mathrm{Ge}$ nanocrystals', Phys. Rev. B,71( 2005).

[19] Weissker H. Ch., Furthmu" ller J., Bechstedt F.: 'Structure- and spindependent excitation energies and lifetimes of $\mathrm{Si}$ and $\mathrm{Ge}$ nanocrystals from ab initio calculations', Phys. Rev. B, 69(2004). [20] S. M. Sze and K. K. Ng, "Physics of semiconductor devices", $3^{\text {rd }}$ edition, Wiley (2007). 